\title{
ALTERNATIVAS PARA CREDITAÇÃO CURRICULAR DA EXTENSÃO: DEFINIÇÕES CONCEITUAIS E ANÁLISE NORMATIVA
}

\author{
Edson José NEVES JÚNIOR ${ }^{i}$ \\ Jaqueline MAISSIAT ${ }^{\text {ii }}$
}

\begin{abstract}
RESUMO
Este artigo tem dois objetivos, o de apresentar uma discussão sobre a definição conceitual-normativa da dimensão de extensão do Ensino Superior; e analisar como a creditação da extensão tem sido implementada nas Instituições de Ensino Superior do País, desde que se tornou medida obrigatória disposta em regulamento nacional a partir de 2018. A respeito do primeiro propósito, a concepção atual de extensão é abrangente, polissêmica e, na medida do possível, neutra, permitindo sua instrumentalização na rede de Ensino Superior com base em interpretações múltiplas de sua natureza. A respeito do segundo objetivo, entre os modelos de curricularização verificados, percebe-se que alguns procuram seguir uma orientação mais transformadora e coerente com as propostas de curricularização da extensão e outros apenas se adaptam à pressão por alteração de acordo com condições próprias.
\end{abstract}

PALAVRAS-CHAVE: Extensão; Creditação da extensão; Reforma universitária.

\section{ALTERNATIVES FOR CURRICULAR CREDITATION OF EXTENSION: CONCEPTUAL DEFINITIONS AND NORMATIVE ANALYSIS}

\begin{abstract}
The article has two objectives, to present a discussion about the conceptual-normative definition of the Extension dimension of higher education; and to analyze how the Extension accreditation has been implemented by Higher Education Institutions in Brazil, considering it became a mandatory measure demanded by national regulation since 2018. Regarding the first purpose of this study, the current concept of Extension is all-encompassing, polysemic and, as long as it is possible, neutral, allowing its instrumentalization in the higher education system from multiple interpretations of its nature. As for the second objective, among the verified curricularization models, it is noticed that some institutions seek to follow a more transformative and coherent orientation from the extension's curricularization proposals, while others simply adapt it under the pressure of a demand for change according their own circumstances.
\end{abstract}

KEYWORDS: Extension; Mandatory extension credits; University reform.

\footnotetext{
${ }^{\text {i }}$ Doutorado em Estudos Estratégicos Internacionais pela Universidade Federal do Rio Grande do Sul (UFRGS). Professor do Instituto de Economia e Relações Internacionais da Universidade Federal de Uberlândia. E-mail: edson.neves@ufu.br - ORCID iD: https://orcid.org/0000-0002-0532-5555.

ii Doutorado em Informática na Educação pela Universidade Federal do Rio Grande do Sul (UFRGS). Professora do Instituto Federal do Triângulo Mineiro e do Instituto Federal do Espírito Santo. E-mail: jaquelinemaissiat@iftm.edu.br - ORCID iD: https://orcid.org/0000-0002-9124-4267. 


\section{ALTERNATIVAS PARA LA ACREDITACIÓN CURRICULAR DE EXTENSIÓN: DEFINICIONES CONCEPTUALES Y ANÁLISIS NORMATIVO}

\section{RESUMEN}

El artículo tiene dos objetivos, presentar un debate sobre la definición conceptual-normativa de la dimensión de la extensión en la educación superior; y analizar cómo se ha implementado la acreditación de la extensión en las instituciones de educación superior de Brasil, ya que se convirtió en una medida obligatoria prevista en la regulación nacional desde 2018. En cuanto al primer fin, la concepción actual de la Extensión es integral, polisémica y, en la medida de lo posible, neutra, permitiendo su instrumentalización en la red de educación superior a partir de múltiples interpretaciones de su naturaleza. Sobre el segundo objetivo, entre los modelos de curricularización verificados, se percibe que algunos buscan seguir una orientación más transformadora y coherente con las propuestas de curricularización de la extensión, y otros sólo adaptan a la presión mediante alteración según sus propias condiciones.

PALABRAS CLAVE: Extensión; Créditos de extensión obligatorios; Reforma universitária.

\section{INTRODUÇÃO}

A extensão universitária ostenta uma posição marginalizada no meio acadêmico, se consideradas as outras dimensões fundamentais da Educação Superior: o Ensino e a Pesquisa. Ao mesmo tempo, anima discussões polêmicas em virtude de sua recente valorização com a obrigatoriedade de sua creditação nos currículos dos cursos de graduação. Compreendida como política de incentivo à integração entre sociedade e academia, a extensão encerra em sua natureza a abertura e envolvimento das Instituições de Ensino Superior (IES) com organizações sociais diversas. Embora tal conexão expresse um movimento de democratização salutar e ajustado aos valores republicanos básicos, a transformação que demanda se contrapõe às práticas há muito enraizadas do fazer universitário - algumas negativas, outras positivas.

As atividades realizadas em IES sempre estiveram conectadas com suas correspondentes formações sociais. A instrução e a qualificação de intelectuais e profissionais derivados da dimensão "Ensino" e a produção de conhecimento da função "Pesquisa" serviram (e servem) direta e indiretamente às comunidades externas, a empresas privadas, a organizações não estatais e ao setor público. Entretanto, como regra, a publicidade a respeito dessas contribuições nem sempre é evidente. Os múltiplos filtros estabelecidos entre o que a Ciência cria nos laboratórios e nas salas de aula e seus resultados objetivos implementados na 
sociedade invisibilizam as IES para a opinião pública. Adicione-se a isso o comportamento tradicional de pesquisadores em atribuir pouca relevância à divulgação ampla e didática de suas investigações, marcadas pela hiperespecialização.

A extensão, como um esforço contemporâneo para reverter esse quadro, serviria não apenas para tornar acessíveis as produções acadêmicas, mas principalmente por alterar a essência das IES em sua relação com a comunidade externa. A forma dessa nova "reforma" seria a creditação da extensão, com sua introdução compulsória nos currículos de todos os cursos de graduação no Brasil. Ao determinar o envolvimento amplo da comunidade acadêmica com a sociedade, marcado pelos princípios da dialogicidade, da interdisciplinaridade e da articulação com o Ensino e a Pesquisa, está-se propondo uma nova maneira de inserção significativa, na qual a transformação mútua se torna a regra. Contudo, como se verá, o modo como a creditação da extensão foi regulamentada tem gerado polêmicas e resistências.

Para atender aos objetivos propostos, o artigo se divide em três seções, além de Introdução e Conclusão. Na primeira parte, é realizada uma discussão conceitual da extensão a partir da definição constante em documentos recentes, nos quais se estrutura essa dimensão a partir de alguns fundamentos. Na seção seguinte, é apresentada a proposta de creditação curricular, bem como suas virtudes e motivos da resistência no meio acadêmico. No item final do texto, são apontadas e avaliadas as alternativas de curricularização da extensão propostas em instrumentos normativos aprovados pelas IES.

\section{DEFINIÇÃO CONCEITUAL-NORMATIVA ATUAL DA EXTENSÃO}

O desenvolvimento histórico da extensão condicionou variações em sua conceituação, que é, por definição, abrangente, heterogênea e polissêmica. Assim, em consonância com a multiplicidade característica das próprias IES e para dar conta da amplitude categórica da extensão, a legislação brasileira, visando à sua instrumentação, optou por uma caracterização igualmente genérica, ao mesmo tempo que manteve certos fatores básicos. A polissemia do termo, como indicado anteriormente, deve-se à sua própria complexidade histórica, à tipificação diversa sobre a natureza da Educação Superior no Brasil e à necessidade de abranger a pluralidade em um regramento geral. Essa condição é reconhecida no parecer da 
Câmara de Educação Superior (CES), vinculada ao Conselho Nacional de Educação (CNE), nas discussões para aprovação das referidas Diretrizes, ao afirmar que a

[...] extensão, uma das funções precípuas da universidade, está condicionada a diferentes concepções e práticas, além de cercada por dicotomias, contradições e conflitos. Tê-la, portanto, como um dos seus pilares, tem sido alvo de posições críticas e proposições de toda ordem (BRASIL, 2018a).

Considerando o marco regulatório aprovado pelo CNE/CES, que determina as Diretrizes para as Políticas de Extensão da Educação Superior Brasileira, a definição mais recente da extensão pode ser verificada nos trechos a seguir, que integram a Resolução 07/2018 do CNE:

Art. 3. ${ }^{\circ}$ A Extensão na Educação Superior Brasileira é a atividade que se integra à matriz curricular e à organização da pesquisa, constituindo-se em processo interdisciplinar, político educacional, cultural, científico, tecnológico, que promove a interação transformadora entre as instituições de ensino superior e os outros setores da sociedade, por meio da produção e da aplicação do conhecimento, em articulação permanente com o ensino e a pesquisa.

Art. 5. ${ }^{\circ}$ Estruturam a concepção e a prática das Diretrizes da Extensão na Educação Superior: I - a "interação dialógica" da comunidade acadêmica com a sociedade por meio da troca de conhecimentos, da participação e do contato com as questões complexas contemporâneas presentes no contexto social; II - a "formação cidadã" dos estudantes, marcada e constituída pela vivência dos seus conhecimentos, que, de modo "interprofissional e interdisciplinar", seja valorizada e integrada à matriz curricular; III - a produção de "mudanças na própria instituição superior e nos demais setores da sociedade", a partir da construção e aplicação de conhecimentos, bem como por outras atividades acadêmicas e sociais; IV - a "articulação entre ensino/extensão/pesquisa", ancorada em processo pedagógico único, interdisciplinar, político educacional, cultural, científico e tecnológico (BRASIL, 2018b, p. 34, grifo nosso).

Importante ressaltar que a definição presente na Resolução 7/2018 do CNE, por sua vez, é uma síntese desenvolvida a partir do que consta na Política Nacional de Extensão Universitária, de 2012, iniciativa do Fórum de Pró-Reitores das Instituições Públicas de Educação Superior Brasileiras (FORPROEX, 2012).

A caracterização disposta no art. $5^{\circ}$, conectada a elementos presentes em outros trechos da norma, constituem a essência do texto e representa a visão contemporânea sobre extensão. Cada elemento destacado na citação merece uma explicação contextualizada. Primeiro, a interação dialógica entre IES e sociedade. Essa orientação implica o envolvimento 
horizontal e ativo da comunidade acadêmica com a comunidade externa na preparação, execução e avaliação das ações de extensão. Opõe-se a (e pretende superar) certas interpretações conservadoras, nas quais a sociedade era mera receptora de contribuições elaboradas no âmbito universitário. Inclusive, no passado, tal acepção auxiliou na efetivação de uma concepção unilateral, segundo a qual eventos acadêmicos, como seminários e palestras, eram classificados como extensão por estarem "abertos à comunidade". A interação dialógica, por outro lado, pressupõe necessidades e possibilidades mútuas, planejamento e realização conjuntos, e ação direta de docentes, técnicos e discentes.

Segundo, estimular a formação estudantil cidadã, interdisciplinar e interprofissional, pressupõe, a princípio, a valorização dos conhecimentos prévios dos discentes e sua transformação e aperfeiçoamento pela ação na sociedade civil. Por sua vez, o binômio interdisciplinar/interprofissional sugere o condicionamento crítico, qualificado e abrangente da intervenção social. Como aponta o documento da Política Nacional de Extensão Universitária:

Por muitas décadas, as tecnologias de intervenção social têm oscilado entre visões holísticas, destinadas a apreender a complexidade do todo, mas condenadas a ser generalistas, e visões especializadas, destinadas a tratar especificidades, mas caracterizadas pelo parcelamento do todo. A diretriz de Interdisciplinaridade e Interprofissionalidade para as ações extensionistas busca superar essa dicotomia, combinando especialização e consideração da complexidade inerente às comunidades, setores e grupos sociais, com os quais se desenvolvem as ações de Extensão, ou aos próprios objetivos e objetos dessas ações (FORPROEX, 2012, p. 31).

O pilar da transformação social, o terceiro princípio, está presente na proposta de mudança mútua decorrente da interação academia e sociedade. Entretanto, pela própria definição genérica e polissêmica da extensão, o conteúdo da transformação conjunta não tem desdobramento claro e preciso. A proposição, portanto, abre margem para a extensão em suas múltiplas concepções. Pode significar o ato mercantil representado pelo desenvolvimento conjunto de produtos, prestação de serviços ou oferta de "soluções criativas" para o setor privado, prática antiga nas relações entre a IES e a sociedade (PAULA, 2013). Em outro entendimento, pode caracterizar a alteração social de cunho reformista e assistencialista, também histórica, na qual a academia prepara mão de obra adequada, e minimamente crítica, ao mercado de trabalho ou oferece serviços de melhoria solicitados pela sociedade (LAWRIE, 
2014; JONES; GARFORTH, 1998). Ainda, tem-se a abordagem crítica e, de fato, transformadora, segundo a qual intelectuais orgânicos e movimentos sociais engajados se comprometem com uma nova forma de organização social e percebem suas ações articuladas para um projeto político mais amplo. Essa noção profunda de extensão foi bem formulada por Freire (1983) no livro Extensão ou comunicação?, a respeito da extensão no campo e da relação entre especialista agrônomo e o trabalhador rural. Por óbvio, no contexto da redação do livro, pela primeira vez publicado em 1969, o educador era bastante crítico do termo "extensão", marcado pela verticalidade acadêmica e pelo tecnicismo.

Por fim, há ainda o preceito da indissociabilidade do Ensino, Pesquisa e Extensão, que procura tornar as ações extensionistas significativas. Em outras palavras, que a extensão, enunciada como transformadora e horizontal, esteja articulada às funções básicas da academia para reformulá-las em um projeto compreensivo de inserção social. Dessa forma, evita que essa dimensão não se converta apenas em instrumento de mobilização da mão de obra estudantil para ações assistencialistas ou mero aproveitamento de inovações tecnológicas e administrativas para o mercado. Em realidade, minorada nas discussões valorativas da maior interação entre academia e sociedade, a referida "indissociabilidade" tem pretensões mais amplas: flexibilizar o currículo para fugir da compartimentação disciplinar e tornar, assim, o processo de aprendizagem (ensino) e a produção de conhecimento (pesquisa) permanentemente vinculado à sociedade (extensão). Trata-se, então, de uma reforma mais ampla das instituições de educação superior, impactante tanto em sua forma de organização quanto em sua substância (CARNEIRO; COLLADO; OLIVEIRA, 2014; MAZZILLI, 2011; MACIEL, 2010).

Essa definição mais detalhada da extensão, resultado de uma evolução inserida no processo maior da reforma do Ensino Superior, agora pretende ser incorporada e instrumentalizada via alteração das matrizes curriculares. A citada Resolução 7/2018 é clara ao orientar a reforma dos currículos de graduação para que atividades de extensão representem, no mínimo, $10 \%$ da carga horária total dos cursos. A aplicação da curricularização da extensão deverá ser operacionalizada nas modalidades mais gerais permitidas pela legislação nacional sobre o assunto, desde que respeitem sua concepção mais atual, que determina o envolvimento direto da sociedade. Entretanto, há resistências 
substantivas ao processo e, como se verá, muitos dos argumentos de oposição se amparam na crítica aos procedimentos e à natureza da proposta de mudança.

\section{CREDITAÇÃO DA EXTENSÃO: VIRTUDES E RESISTÊNCIAS}

Embora seja uma dimensão essencial do Ensino Superior, a extensão no Brasil enfrenta dificuldades substantivas para se consolidar. A ausência de tradição e exercício prático entre docentes, técnicos administrativos e discentes, a polissemia conceitual dessa dimensão universitária, o reduzido aporte orçamentário indutivo e a percepção do ensino e eesquisa como contributos suficientes da academia para a sociedade são alguns dos motivos pelos quais a extensão figura como ideia e exercício ainda secundários no mundo universitário (IMPERATORE; PEDDE, 2015). Pensando em sua valorização, mas também na maior articulação com a comunidade externa às IES, as direções universitárias, a administração pública educacional, os movimentos estudantis e as associações vinculadas ao Ensino Superior têm estimulado o debate, desde o final dos anos 1990, sobre a creditação da extensão. Tal processo nada mais é que sua transformação em atividade obrigatória, inserida nas matrizes curriculares dos cursos de graduação do País. Para analisar o evolver desse processo, foram selecionados textos básicos da Educação Superior, como os Planos Nacionais da Educação de 2001 e 2014, e a mais recente Resolução 7/2018 do CNE.

A curricularização da extensão tem uma história relativamente longa; foi pensada como alternativa e inserida como regramento em documentos oficiais da Educação Superior desde o Plano Nacional da Educação (PNE) de 2001. Naquelas circunstâncias, predominava uma concepção assistencialista, funcional e comercial da articulação com a sociedade (IMPERATORE; PEDDE, 2015). A “Meta 23”, específica sobre curricularização da extensão, o que não se consolidou, previa:

Implantar o Programa de Desenvolvimento da Extensão Universitária em todas as Instituições Federais de Ensino Superior no quadriênio 2001-2004 e assegurar que, no mínimo, $10 \%$ do total de créditos exigidos para a graduação no ensino superior no País será reservado para a atuação dos alunos em ações extensionistas (BRASIL, 2001).

O PNE para o período de 2014 a 2024 tem concepção mais genérica sobre a extensão e sua creditação curricular. O sétimo item da "Meta 12" resolve "assegurar, no mínimo, dez por 
cento do total de créditos curriculares exigidos para a graduação em programas e projetos de extensão universitária, orientando sua ação, prioritariamente, para áreas de grande pertinência social". O componente social da norma permite, na prática, a inclusão das várias interpretações conceituais e ações extensionistas que compõem essa função nas IES.

Em sentido complementar, da caracterização social, a Resolução 7/2018, da Câmara de Educação Superior (CES) do CNE, segue a mesma linha e, em seu art. 4..$^{\circ}$ indica que "As atividades de extensão devem compor, no mínimo, 10\% do total da carga horária curricular estudantil dos cursos de graduação, as quais deverão fazer parte da matriz curricular dos cursos". A Resolução também determina que a avaliação das graduações pelo Instituto Anísio Teixeira (INEP) e o recredenciamento das IES no Sistema Nacional de Avaliação (SINAES) devem considerar a modificação dos currículos com a inserção e cumprimento dos $10 \%$ de atividades extensionistas (BRASIL, 2018b). A inovação presente na "Resolução", como mencionado, foi a elaboração de uma tipificação criteriosa herdada da Política Nacional de Extensão, de 2012, na qual constam a "interação dialógica" Universidade-Sociedade, a "interdisciplinaridade" e a "interprofissionalidade", a "indissociabilidade" ensino-pesquisaextensão e a necessidade de "impacto na formação do estudante e na transformação social".

Apesar da evolução conceitual-legal, a obrigatoriedade da extensão nos currículos tem recebido resistências da comunidade universitária por uma série de motivos que, no geral, se referem à sua arbitrariedade funcional, insuficiências orçamentárias, e a seus usos políticos em determinados contextos históricos, entre outros. O primeiro ponto concerne à verticalidade normativa e pretensa aplicação universal indiscriminada. A inserção de atividades extensionistas deveria ser precedida por um amplo debate na comunidade acadêmica brasileira que envolvesse todos os setores e unidades, bem como a sociedade que se intenciona incluir nos assuntos institucionais universitários. A atual definição e objetivos da curricularização extensionista, inversamente, foi resultado da iniciativa do CNE e de fóruns de Pró-Reitores de IES. O parecer da Câmara de Educação Superior sobre as Diretrizes da Extensão é claro a esse respeito, quando trata da política nacional de creditação da extensão:

[...] há de se considerar a lacuna de uma diretriz nacional que promova a unicidade e a consensualidade de concepções e propostas em torno das políticas, das estratégias e das ações pelas quais a extensão universitária brasileira possa ser institucionalizada e implementada (BRASIL, 2018a). 
Outro fator de resistência, passado e presente, refere-se à pretensa universalidade da norma, que estipula a obrigatoriedade de carga horária mínima de $10 \%$ de atividades extensionistas nos currículos dos cursos de graduação. Tal exigência desconsidera: 1. A natureza curricular e o grau de envolvimento social distinto das graduações; 2. A disposição também diferenciada e condicionada do corpo discente para participar de atividades desse tipo, que exige horários alternativos; e 3. As variações orçamentárias devido às políticas governamentais para as IES públicas. Em síntese, alguns cursos possuem maior propensão extensionista, aqui entendida como envolvimento direto com a sociedade civil no processo formativo (ensino) e na produção de conhecimentos (pesquisa). A respeito do ponto 2, discentes matriculados em graduações com dedicação integral poderão se envolver com mais facilidade em ações extensionistas do que discentes de cursos noturnos. Ademais, o envolvimento direto com a comunidade externa compreende incremento orçamental, impossível em cenários, infelizmente recorrentes, de cortes (ou contingenciamentos) de verbas das IES.

Por fim, outro motivo de relutância à aplicação dos $10 \%$ de extensão nos currículos é seu eventual uso político para transformação impositiva e vertical das IES. Para projetos políticos nacionais mais ou menos liberais em essência, o Ensino Superior restritivo e privatizado é a prioridade. Nessas conjunturas, as IES Públicas, a despeito de suas contribuições para a sociedade, tornam-se gasto excessivo. Tanto na proposta de curricularização do início dos anos 2000 quanto na versão atual, uma possibilidade explorada pelas autoridades governamentais é a de que a extensão se converta em instrumento para financiamento, total ou parcial, das IES, o que está em consonância com a visão comercial, de prestação de serviços e de inovação tecnológica, da Extensão Universitária. Nessa perspectiva, fica clara a intenção de submeter o conhecimento produzido no sistema de Ensino Superior aos interesses do mercado, e não da sociedade. Por essas razões, a imposição da extensão nos currículos acaba por ser identificada com programas políticos mais amplos, de compressão e desvalorização da IES pública.

Além desses fatores, Imperatore e Pedde (2015) citam outros potenciais obstáculos situacionais e técnicos para a indução vertical da extensão nas IES. Primeiro, mencionam as dificuldades decorrentes da interação com a sociedade em virtude do academicismo e do autoritarismo universitário. A evolução histórica da Academia, na busca pela complexidade e 
especialização do conhecimento, condicionou seu caráter fechado e autocentrado, crítica sintetizada na ideia da IES como "Torre de Marfim". Associado à hiperespecialização, sobrevém a constatação das dificuldades em fazer com que cientistas comuniquem suas pesquisas e as legitimem perante a opinião pública. Essa limitação levanta questionamentos sobre a relevância da ciência e inflama movimentos políticos contestadores da exclusividade universitária na produção de conhecimento (BARON, 2010; ORESKES; CONWAY, 2010).

Ainda de acordo com os autores, há outro obstáculo no que chamam de "armadilha do currículo, da disciplinaridade, da compartimentalização, que ameaçam a lógica extensionista, seu sentido epistemológico, sua essência crítica e interdisciplinar" (IMPERATORE; PEDDE, 2015, p. 7). Segundo sua defesa, amparada nas discussões atuais, a extensão deve ser pensada não apenas como um transbordamento das atividades de ensino e pesquisa para a sociedade. Pelo contrário, é uma dimensão holística na qual o conhecimento se torna instrumento de transformação conjunta entre academia e sociedade; tendo esse objetivo como referência, a divisão disciplinar tradicional tem pouco a contribuir. Nesse ponto, e considerando a proposta de incorporação dos $10 \%$ nos currículos, a crítica tem fundamento, pois, como se verá a seguir, uma das discussões sobre a creditação da extensão é justamente a criação de disciplinas no formato tradicional, como "Extensão I", “Extensão II" etc., para atender à demanda normativa.

Em sentido contrário, de uma visão positiva da curricularização da extensão, deve-se considerar a conjuntura política do Ensino Superior no Brasil atual. Tendo em vista o fato de que a IES Pública sofre ataques publicitários contundentes contra sua natureza e experimenta cortes injustificados, o resgate da extensão deve ser tratado como ação essencial e salutar justamente por pautar a integração com a sociedade. Movimentação política recente na gestão das IES, em fóruns de reitores e pró-reitores, bem como discussões da comunidade universitária nacional, sugerem que a extensão assume importância renovada. Dessarte, seu estímulo nesse contexto particular tem como objetivos principais: 1. Mobilizar a comunidade interna para apresentar à sociedade as ações desenvolvidas em âmbito acadêmico; 2. Detalhar como as IES contribuem para a formação ampla, humana, complexa e profissional dos discentes; e 3. Dialogar e envolver a sociedade nas atividades regulares das IES públicas. Trata-se, enfim, de amplificar a abertura e o diálogo universitário com múltiplas entidades da sociedade civil para ampliação de seu compromisso social e democrático. 
Outro elemento benéfico da creditação da extensão é sua potencial inserção como mais um capítulo da história da reforma universitária. A transformação do fazer acadêmico não é recente; em não raros momentos do evolver da Educação Superior foram questionados os motivos de sua existência, sua natureza e sua organização (CHARLE; VERGER, 1996). A tipificação sobre que modelo de IES é o mais adequado constitui matéria de intenso debate entre especialistas, sem, contudo, alcançar nenhuma definição rigorosa (WOLFF, 1993). Nessa discussão, a abertura e a democratização ocupam lugar de destaque pela condição de pertencimento social das IES em regimes republicanos - afinal, se as instituições integram o quadro político de sociedades heterogêneas e participativas, por que não as tornar inclusivas e acessíveis? A incorporação da extensão como atividade regular das graduações pode, na esteira das propostas de aprimoramento, se configurar um instrumento indutor da transformação.

Desde a aprovação da Resolução 7/2018 pelo CNE, em paralelo à necessidade de maior aprendizado sobre a abertura para a sociedade (ou seja, a própria ideia de extensão), uma das preocupações centrais das IES diz respeito à forma como implantar e implementar a creditação de ações extensionistas nos currículos acadêmicos. Na seção seguinte, são apresentadas e analisadas algumas das alternativas assumidas por instituições selecionadas. Contudo, a crítica aos modelos se restringe às considerações presentes nas normativas oficiais, visto que práticas derivadas da curricularização são recentes e a produção bibliográfica correlata, capaz de avaliar seus impactos, ainda é exígua.

\section{ALTERNATIVAS PARA A CURRICULARIZAÇÃO DA EXTENSÃO}

As propostas a seguir foram estruturadas a partir da leitura dos programas de curricularização de IES divulgados em seus sítios eletrônicos. Em síntese, a creditação da extensão tem assumido, até o momento, três formatos. As alternativas identificadas são: primeira, a criação de disciplinas de extensão; segunda, vincular atividades de Extensão a disciplinas já existentes; e terceira, constituição de programa de extensão institucional vinculado às unidades acadêmicas. Além dessas opções, foi indicada uma legislação acadêmica que demonstra caráter aberto e flexível para permitir a instrumentalização de qualquer dos tipos de creditação citados, isolados e combinados, ou outros formatos. Tais 
opções, aqui separadas em itens específicos apenas para fins didáticos, não são excludentes e, inclusive, todas podem compor um plano integrado para reforma das matrizes curriculares.

Para tanto, foram seguidos os princípios básicos constantes na Política Nacional de Extensão Universitária de 2012 (FORPROEX, 2012), no Plano Nacional de Educação 20142024 (BRASIL, 2015) e na Resolução 7/2018 do CNE (BRASIL, 2018b). De forma geral e como já demonstrado em seção própria, tais fundamentos extensionistas são: a "interação dialógica" universidade-sociedade; a "interdisciplinaridade" e a "interprofissionalidade", a "indissociabilidade" ensino-pesquisa-extensão e a necessidade de "impacto na formação do estudante e na transformação social”.

Por ser uma análise direcionada à introdução e execução da creditação da extensão, a opção foi pela descrição e análise de propostas já aprovadas (ou em fase final de validação) em outras IES. As fontes principais consultadas foram, então, documentos normativos.

\subsection{Criação de disciplinas de extensão}

A criação de disciplinas específicas de extensão surgiu como alternativa em algumas propostas de curricularização. Pressupõe a inserção de novas unidades curriculares com nomenclatura e carga horária próprias, com aumento ou não da carga horária do curso, desde que a extensão represente $10 \%$ desse total. Nessa categoria, a distribuição das disciplinas aos docentes segue padrão normal da oferta semestral e as atividades de extensão devem ser registradas, de acordo com seu tipo, pelo docente no sistema digital destinado a essa finalidade. Outra possibilidade é atribuir tais disciplinas a mais de um professor, cada qual assumindo ações extensionistas em consonância com suas formações e experiências.

Um modelo de "Disciplina de Extensão" foi regulamentado na Universidade Federal de Santa Catarina (UFSC), em documento publicado no início de 2020. Segundo essa proposta, em seu art. $6^{\circ}$, inciso I, as atividades de extensão podem ser cumpridas "como 'disciplina da matriz curricular', que dedicará toda ou parte da carga horária de um período letivo à realização de atividades de extensão previstas em um ou mais programas de extensão". Ademais, a Resolução determina que "As atividades de extensão desenvolvidas como disciplina da matriz curricular deverão estar integradas a um ou mais programas de 
extensão descritos no PPC e deverão estar registrados no sistema de registro de ações de extensão da UFSC" (art. 7. ${ }^{\circ}$ ).

A referida norma, a Resolução Normativa 01/2020, da Câmara de Graduação, ainda possibilita, como descrito, que apenas parte da carga horária de uma disciplina seja destinada à extensão. Em outro trecho, indica que a curricularização pode ocorrer também, alternativamente, como "atividade de extensão na forma de unidade curricular, constituída de ações de extensão em 'projetos, cursos e eventos"”. Portanto, conforme esse regramento, nas unidades acadêmicas é possível instituir somente disciplinas de extensão, ou transformar parte da carga horária das disciplinas regulares em extensão; ou ainda elaborar um programa institucional de extensão para as unidades administrativas, (departamento/instituto ou apenas cursos) composto por "projetos, cursos e eventos" (UFSC, 2020).

Como experiências publicadas de curricularização da extensão se restringem ao nível de cursos, e como a referida creditação, realizada de maneira sistemática e universal, consta apenas em documentos, a análise se limita a textos normativos. Uma vantagem funcional da disciplina integral de extensão seria a garantia de carga horária em decorrência de sua obrigatoriedade - os discentes teriam de cursá-las e haveria docentes designados.

Contudo, ao mesmo tempo que a certeza da constância figura como ponto positivo, converte-se também em prejuízo na medida em que se corre o risco da responsabilização definitiva de um grupo de professores pela "oferta de extensão" da Unidade. No atual modelo de segmentação disciplinar, é comum a assunção de disciplinas por afinidade. Por via de regra, especialistas em determinada subárea do conhecimento desenvolvem pesquisas e ministram matérias nas quais possuem competência reconhecida, o que proporciona a construção de uma identidade acadêmica consolidada. Inclusive, essa é uma característica valorizada pela comunidade epistêmica e por agências de fomento. No entanto, no caso da extensão ofertada em disciplinas, esse não é um caminho adequado em razão do caráter abrangente e interdisciplinar pretendido. Se disciplinas extensionistas forem assumidas por um limitado número de professores, sem rotatividade regulamentada, a tendência é sua continuidade prática, bem como a restrição da extensão aos temas nos quais aquele coletivo docente tenha expertise.

É oportuno resgatar a crítica de Imperatore e Pedde (2015, p. 7) sobre a "armadilha do currículo, da disciplinaridade, da compartimentalização, que ameaçam a lógica extensionista, 
seu sentido epistemológico, sua essência crítica e interdisciplinar”. De acordo com os autores, e também com a "Política Nacional de Extensão Universitária" (FORPROEX, 2012), um dos aspectos fundamentais da mudança na relação entre IES e sociedade reside na defesa de seu caráter interdisciplinar e interprofissional. Tal proposição se assenta na constatação de que para interferir na realidade social, complexa por essência, seria insuficiente e equivocado operar apenas por instrumentos compartimentados e hiperespecializados das disciplinas acadêmicas. Em sentido contrário, o emprego de saberes interdisciplinares, organizados em programas abrangentes de extensão, configura a alternativa mais ajustada. Assim, a proposta da disciplinarização da extensão conflita com sua intenção transformadora mais básica.

Além dos problemas conceituais, há dificuldades técnicas na criação de disciplinas para essa categoria, como: 1. Sobreposição de carga horária para docentes e discentes, pois cada matéria tem uma atribuição oficial de horas e as ações extensionistas desenvolvidas nessas disciplinas terão também carga horária própria; e 2. Dificuldade de estabelecimento de parcerias, contrapartidas e financiamento de atividades de extensão com organizações externas, visto que as disciplinas estão inseridas na função Ensino, para a qual já existe previsão orçamentária própria. Por essas razões, a disciplinarização da extensão figura como uma opção possível do ponto de vista regulamentar, mas não é recomendável pela sua incompatibilidade com a natureza desejada para a inclusão da extensão nos currículos.

\subsection{Vinculação de atividades de extensão às disciplinas existentes}

A inserção da extensão em disciplinas já existentes tem se mostrado uma alternativa interessante para graduações que já possuem número substantivo de atividades práticas suscetíveis de ser classificadas como extensão. Nesses casos, trata-se de alterar a caracterização dos componentes empíricos ajustáveis à extensão, desde que não impacte a carga horária prática mínima exigida nas Diretrizes Curriculares Nacionais do curso ou em outro regime regulatório.

No documento "Guia para curricularização das atividades de Extensão nos cursos de graduação da Universidade Federal de São Paulo”, publicado em 2017, consta o processo interno para averiguação dos caminhos da creditação. Para atingir esse objetivo foi formada uma comissão que concluiu: 
[...] nas reuniões realizadas com os cursos de graduação, ouvindo os relatos dos docentes sobre as atividades que eram desenvolvidas no âmbito das UC [Unidades Curriculares] dos cursos, constatou-se que, na sua grande maioria, era possível identificar unidades curriculares de caráter extensionista, isto é, unidades curriculares em que eram desenvolvidas atividades eminentemente extensionistas ou que preparavam os alunos para essa realização. A partir disso, avaliou-se, então, que seria possível reconhecer parte da carga horária dessas UC, ou mesmo o total de sua carga horária, como de natureza extensionista e, desse modo, validar os correspondentes créditos curriculares como atividades de extensão (UNIFESP, 2017, p. 13).

Assim, desde então, a Universidade tem realizado um levantamento, por cursos, da quantidade de horas caracterizáveis como extensão e convertido a classificação atual para atender à proposta de creditação explicitada na Resolução 7, do CNE. Em resumo, trata-se de uma adequação técnica na qual a carga horária antes assinalada como prática será convertida e registrada como extensão de modo a atingir $10 \%$ do total de créditos do curso.

Como adiantado no início desta subseção, a opção pela associação de extensão a disciplinas é vantajosa e, portanto, positiva em graduações nas quais a carga horária prática seja substantiva a ponto de tornar a substituição possível. No caso de promover a inserção de extensão em disciplinas existentes a partir do zero, devem-se observar alguns fatores: 1. A compatibilidade entre os conteúdos da disciplina e das ações de extensão a ela associada; 2. A disponibilidade de o docente oferecer acompanhamento à turma tanto nas aulas regulares quanto nas atividades externas; 3. O adequado incremento da carga horária da disciplina, considerando a incorporação de componentes curriculares distintos, bem como os cuidados na distribuição da oferta de disciplinas para o corpo docente; e 4. O alinhamento das ações de extensão com as diretrizes do plano de extensão da unidade acadêmica e da IES.

De todo modo, nas atuais condições de cursos com reduzida atividade prática curricular, como o são as graduações pertencentes à grande área de Humanidades, o ideal seria que a associação de extensão a disciplinas viesse acompanhada de alternativas. Nesse sentido, a creditação deve ser antecedida pelo levantamento de quais professores já oferecem, ou têm interesse em ofertar, ações interativas entre IES e sociedade em suas disciplinas para aproveitar o potencial existente na Unidade.

\subsection{Programa de Extensão Institucional nas unidades acadêmicas}


A oferta periódica de ações de extensão, como projetos, cursos, eventos e prestações de serviços, de realização em curto e médio prazos, organizados em um Programa abrangente, configura a alternativa institucional flexível e interdisciplinar escolhida por algumas IES. Com oferta regular e organizada nas unidades acadêmicas (institutos, faculdades, escolas) ou nas subunidades (cursos, departamentos), essa alternativa propicia a estruturação da extensão, ao mesmo tempo, separada formalmente e integrada de fato às dimensões de ensino e pesquisa. Em um cenário ideal, a organização de Programas seria administrada segundo um sistema periódico e rotativo de docentes, diretamente responsáveis por oferecer ações de extensão e/ou mobilizar discentes, técnicos e outros professores para esse objetivo, desde que a oferta atenda à carga horária mínima estipulada para o período determinado.

A preferência por esse modelo se manifestou em diversos documentos de creditação da Extensão Universitária. A Universidade Federal de Pernambuco - UFPE (2017), por exemplo, criou em seu regramento a seguinte possibilidade:

Art. 1. ${ }^{\circ}$ Vincular, nos Projetos Pedagógicos dos Cursos (PPC), o mínimo de $10 \%$ da carga horária total de integralização dos Cursos de Graduação, na forma de Ação Curricular de Extensão (ACEx). [...]

$\S 2 .^{\circ}$ Compreende-se como Ação Curricular de Extensão (ACEx), ações executadas em forma de Programas e Projetos, com carga horária determinada na matriz curricular, independentemente da periodização letiva.

Na sequência, complementam a norma ao autorizar que as modalidades "cursos" e "eventos" sejam considerados ACEx, desde que haja "participação do discente na organização e/ou execução destes" (UFPE, 2017).

A Universidade Federal de Alagoas - UFAL (2018) adotou padrão parecido e se preocupou em detalhar a proposta para as unidades acadêmicas na forma de "Atividades Curriculares de Extensão - ACE”. Na UFAL, os Programas de extensão devem ser compostos por, no mínimo, três tipos distintos de atividade extensionista, sendo pelo menos dois deles na categoria de "Projetos", com duração mínima de dois semestres, e contemplar áreas de conhecimento diferentes, entre as indicadas no Projeto Pedagógico do Curso (PPC). Além de fatores condizentes com a proposta geral da Extensão, relacionados à formação estudantil cidadã, interação dialógica universidade-sociedade, interdisciplinaridade/interprofissionalidade e articulação Ensino-Pesquisa-Extensão, o texto 
apresenta caráter social inequívoco. Para ser aprovado, de acordo com o inciso $\mathrm{V}$ da norma, o "Programa" dos cursos deve:

Ser desenvolvido junto a uma comunidade, movimento social, instituição pública ou entidade que desenvolva atividades com comunidades em vulnerabilidade (preferencialmente no entorno da UFAL), cuja escolha deve ter clara justificativa e demonstrada viabilidade de desenvolvimento.

A normativa da UFAL se ajusta bem à diretriz que trata do viés social da extensão, consagrado nos debates especializados e nos documentos orientadores da área. Por sua natureza, estabelece uma identidade particular à IES na articulação com a sociedade e, ao mesmo tempo, impede a instrumentalização da extensão em um formato empresarialcomercial. Podemos constatar que a regra indica dificuldades em sua implementação para alguns setores, visto que as IES congregam visões e perfis bastante divergentes a respeito da relação com as organizações da comunidade externa. A caracterização social, embora amparada em normas gerais, pode apresentar resistências pontuais justamente pela sua restrição.

Na mesma linha, a Universidade Federal de Minas Gerais - UFMG (2015) criou o componente curricular "Formação em Extensão Universitária". Tal categoria está restrita às modalidades de Programas e Projetos, é voltada às comunidades externas, "visando à melhoria sustentável de indicadores sociais e do acesso à educação, à saúde e à cultura", e suas ações "serão desenvolvidas preferencialmente junto a comunidades com baixo Índice de Desenvolvimento Humano". Aqui, ao contrário do descrito para a UFAL, a ressalva do "preferencialmente" torna o regulamento mais flexível e permite alternativas de creditação mais abrangentes. Ainda, como processo de avaliação das ações desenvolvidas, foi estipulada a realização de seminários nos quais os discentes "apresentarão os resultados e farão a respectiva análise crítica" de suas ações.

Os méritos da alternativa de criação de um Programa Geral de Extensão para unidades ou subunidades acadêmicas são evidentes: 1. Atende aos princípios estruturantes do conceito atual de extensão; 2. Possui flexibilidade; 3. Pode se articular a outras modalidades de creditação (disciplinas de extensão e/ou ações de extensão vinculadas às disciplinas); 4. Permite que se criem parcerias e contrapartidas com entidades externas, bem como possibilita 
a concorrência por financiamento em agências de fomento; e 5. Se adotado o padrão de rotatividade, tem potencial para envolver parte substantiva de docentes, técnicos e discentes.

Um possível obstáculo seria o fato de que, ao contrário das disciplinas de extensão ou da extensão vinculada a disciplinas, eventuais programas de extensão não estariam oficialmente atribuídos a docentes, técnicos ou discentes. O compromisso da comunidade universitária com essa proposta deriva, todavia, da compreensão sobre o tipo de transformação da relação desejada entre IES e sociedade, o que, por sua vez, demanda debates abertos a respeito das expectativas que se têm sobre o papel da Academia no Brasil atual.

\subsection{Normatização aberta e flexível para creditação da extensão}

Em outros casos, a normatização da curricularização da extensão segue um padrão aberto e inclusivo, quando se trata das alternativas de creditação. No caso da Universidade Federal de Uberlândia (UFU), está regulamentada pela Resolução 13/2019 do Conselho de Graduação. Conforme esse documento, foi criado um novo componente curricular intitulado “Atividades Curriculares de Extensão", que atende aos fundamentos teóricos da extensão e se ajusta às demandas para incorporação nos currículos o mínimo de $10 \%$ de atividades de extensão. Quanto aos procedimentos formais, a análise do texto demonstra que a proposta engloba todos os elementos básicos presentes em regimentos de outras instituições, como a obrigatoriedade de coordenação docente de ações de extensão e do registro em um sistema digital. Com relação ao conteúdo diretivo, ou seja, as orientações sobre como cada curso deve promover a alteração dos PPCs para fins de creditação, fica claro o caráter compreensivo e flexível da norma. Nos $\S \S 2 .^{\circ}, 4 .^{\circ}$ e $5 .^{\circ}$ do art. $4 .^{\circ}$ está disposto:

$\S 2 .^{\circ}$ O Projeto Pedagógico de Curso deverá apresentar a forma como o componente curricular Atividades Curriculares de Extensão será operacionalizado, articulado com o ensino e a pesquisa, bem como as formas de registro e os critérios de aproveitamento e convalidação de atividades de extensão realizadas pelo graduando.

$\S 4 .^{\circ}$ Os estudantes poderão participar de quaisquer atividades de extensão, mantidas pela UFU, respeitado o disposto no projeto pedagógico do respectivo curso de graduação.

$\S 5 .^{\circ}$ As Atividades Curriculares de Extensão poderão ser desenvolvidas pelo graduando em qualquer momento, durante o curso respeitado o disposto no projeto pedagógico do respectivo curso de graduação (UFU, 2019, p. 3). 
Ao determinar que as "Atividades" serão operacionalizadas pelos PPCs $\left(\S 2 .^{\circ}\right)$, a Resolução permite que qualquer das alternativas de creditação demonstradas nas seções anteriores deste texto seja implementada. Assim, são franqueados: a criação de disciplinas de extensão; a vinculação de ações de extensão a disciplinas existentes; e a constituição de um Programa de Extensão institucional na unidade acadêmica. O disposto no $\S 4 .^{\circ}$ valoriza o caráter interdisciplinar da extensão ao liberar o corpo discente para participar de atividades promovidas por outras unidades acadêmicas da UFU. Por fim, o último parágrafo impõe obstáculos à modalidade "disciplinas de extensão" porque autoriza aos discentes se inscreverem nas Atividades em qualquer momento durante a realização de sua graduação. Entretanto, essa é uma dificuldade que pode ser contornada via disposição de unidades curriculares "eletivas obrigatórias", ou seja, disciplinas cursadas pelo discente em semestre de sua escolha, desde que ofertada.

A abertura e a flexibilidade da legislação da UFU são importantes porque atende às particularidades de suas graduações e permite aproveitar práticas identificáveis com extensão para conversão. Algumas das IES têm optado por flexibilizar o processo de creditação da extensão, sugerindo aos cursos a reformulação dos PPCs com a possível inserção de modalidades diversas de extensão. Apenas a título de exemplo, a Universidade Federal de Pelotas - UFPel (2016) orientou os colegiados das graduações pela curricularização específica ou combinada a partir de duas alternativas elementares: 1. A formalização nos PPCs de Programas, Projetos e ações de extensão ofertados com regularidade, que constituirão o componente intitulado "Atividades Curriculares em Extensão"; e/ou 2. O desenvolvimento de ações de extensão dentro de disciplinas, com caracterização específica da carga horária prática destinada a essa finalidade. O texto também sugere o aproveitamento como extensão de parte da carga horária de estágios obrigatórios.

Considerando as alternativas listadas, algumas observações são necessárias. Primeiro, a despeito da fixação normativa dos $10 \%$ de atividades de extensão nos currículos, a creditação da extensão tem se mostrado um processo flexível, ajustado às características das instituições e das especificidades de seus cursos. Afinal, não poderia ser de outra forma, visto que as IES são espaços plurais de conhecimento. Segundo, para graduações que possuem natureza e carga horária prática destacada, a mudança não gerará transformações substantivas. O aproveitamento de créditos derivados de ações já desenvolvidas para a sociedade via 
mudança de registro tornará os procedimentos de atualização curricular bastante rápidos. Entretanto, nos demais casos com uma identidade mais teórica, a alteração deve ser precedida de ações de conscientização e indução a respeito da extensão. A distinção e as dificuldades da curricularização entre cursos com maior ou menor componente prático de formação são algumas das críticas mais contundentes a respeito da creditação porque ignoram as particularidades. Ao mesmo tempo, apesar de pretender atender à igualdade e à universalidade, contrapõe-se ao princípio da isonomia, porque ignora as condições iniciais de cada curso.

Terceira, na forma como tem sido pensada, a creditação apenas em parte atende aos objetivos mais gerais de transformação dos currículos acadêmicos. A universidade brasileira é caracterizada por uma série de segmentações administrativas-organizacionais e epistemológicas representadas por divisões departamentais diversas e por disciplinas e campos de pesquisa. Essa situação, por sua vez, reflete necessidades bem particulares da gestão acadêmica e da especialização científica, ambas submetidas a um programa amplo dedicado à evolução do conhecimento. A extensão e seu instrumento operacional contemporâneo - a creditação curricular, por outro lado, representam, em essência, uma tentativa de integração das unidades compartimentadas da universidade para possibilitar a intervenção social efetiva. Pelo visualizado nas propostas de curricularização selecionadas, o caminho escolhido consagra as divisões múltiplas existentes nas IES. Mesmo nos casos em que a proposta de programas centralizados, "guarda-chuvas" para ações extensionistas, prevaleceu, percebe-se que a segmentação se torna possível pela oferta de atividades de extensão identificadas com áreas específicas do conhecimento dentro dos cursos. São raros os documentos que determinam de forma clara a necessidade de prévia consulta às comunidades externas para averiguação de suas condições e interesses objetivos e posterior planejamento de projetos de inserção comunitária. De todo modo, essa é uma insuficiência resultante da maneira célere como a creditação foi impulsionada e convertida em normas. A faceta positiva desse conjunto de medidas é que, ao menos, elas estimularam a discussão sobre a reforma universitária com a creditação da extensão.

\section{CONCLUSÃO}


Quando se atua no âmbito educacional a mudança que se pretende por si só já é um processo complexo, pois o que se quer é gerar novos métodos incorporados a fazeres antes já consolidados. Diante das mudanças propostas, via curricularização da extensão, necessitamos estar dispostos a poder enfrentar novos desafios. A IES, pela sua estrutura, propicia esse espaço por ser promotora de formação inicial e continuada e impende fortalecer o tripé que as construiu: ensino, pesquisa e extensão.

São vários os atores (professores, técnicos administrativos, discentes, coordenadores de curso, coordenador de ensino, diretor, coordenador de extensão, pró-reitor, reitor), instâncias (colegiado de curso, núcleo docente estruturante, conselho superior) e setores (coordenadoria de ensino, coordenadoria de extensão, pró-reitoria de ensino, pró-reitoria de extensão) que terão que se articular para atender ao processo de curricularização da Extensão. Estes precisam se envolver para criar condições e regulamentar processos para que tudo seja viável, que ocorra dentro dos trâmites legais e, ainda, que seja oportunizado para todo discente regularmente matriculado.

Faz-se necessária, ainda, a análise de investimentos de: estrutura física (salas de apoio, mobiliário, equipamentos de informática, suplementos de informática, matérias de consumo, entre outros); estrutura virtual (por meio de aquisição de servidores e equipamentos, tratandose da possibilidade de atos extensionistas via plataformas virtuais de aprendizagem, gerenciamento de certificados); e de recursos humanos (equipe de apoio, coordenador de projetos, articulador de convênios, professor supervisor, promotor de ações, desenvolvedor de artes gráficas para divulgação...), seja por meio de contratação de novos servidores ou destinando parte da carga horária para esse fim para que as ações sejam possíveis de execução. Cada área de conhecimento terá suas especificidades e elas precisam ser respeitadas.

De tudo o que podemos observar é que, em circunstâncias que sejam colocadas em prática conforme a resolução indica e com a infraestrutura necessária, a proposta de curricularização da extensão possibilita, ainda, a transposição das barreiras das grandes áreas acadêmicas, proporcionando a tão almejada interdisciplinaridade. Ademais, ajustes substantivos deverão ser realizados para demonstrar a aplicabilidade dos conhecimentos produzidos no âmbito superior tanto para os que estão em formação quanto aos que terão proveito dela: a sociedade; fortalecendo o existir acadêmico e suas múltiplas formações. 
Este estudo pretendeu, portanto, mediante as categorias elencadas (criação de disciplinas de extensão; vinculação de atividades de extensão às disciplinas existentes; programa de extensão institucional nas unidades acadêmicas; normatização aberta e flexível para creditação da extensão), sugerir caminhos na reforma curricular para graduações que ainda não as tenham implementado, ou, ainda, se tornar ponto de reflexão para as que já tenham realizado.

\section{REFERÊNCIAS}

BARON, Nancy. Escape from the Ivory Tower: a guide to making your Science matter. Washington: Island Press, 2010.

BRASIL. Plano Nacional de Educação 2001-2010. Lei n. ${ }^{\circ} 10.172$, de 9 de janeiro de 2001. Disponível em: http://portal.mec.gov.br/arquivos/pdf/L10172.pdf. Acesso em: 2 jul. 2020.

BRASIL. Instituto Nacional de Estudos e Pesquisas Educacionais Anísio Teixeira.

Plano Nacional de Educação PNE 2014-2024: Linha de Base. Brasília, DF: Inep, 2015.

BRASIL. Ministério da Educação. Conselho Nacional de Educação. Câmara de Educação Superior. Parecer CNE/CES n. ${ }^{\circ}$ 608/2018. Estabelece as Diretrizes para as Políticas de Extensão da Educação Superior Brasileira. Parecer Homologado. Portaria n. ${ }^{\circ}$ 1.350. Diário Oficial da União, Brasília, 17 dez. 2018, Seção 1, p. 34, 2018 a.

BRASIL. Ministério da Educação. Conselho Nacional de Educação. Câmara de Educação Superior. Resolução n. ${ }^{\circ}$ 7, de 18 de dezembro de 2018. Estabelece as Diretrizes para a Extensão na Educação Superior Brasileira e regimenta o disposto na Meta 12.7 da Lei n. ${ }^{\circ}$ 13.005/2014, que aprova o Plano Nacional de Educação - PNE 2014-2024 e dá outras providências. Diário Oficial da União, 19 dez. 2018, edição 243, seção 1, p. 49, 2018 b.

CARNEIRO, Patrícia C. O.; COLLADO, Danilo M. S.; OLIVEIRA, Natália F. Extensão universitária e flexibilização curricular na UFMG. Interfaces - Revista de Extensão, v. 2, n. 3, p. 4-26, jul./dez. 2014. Disponível em:

https://periodicos.ufmg.br/index.php/revistainterfaces/article/view/18951. Acesso em: 2 jul. 2020.

CHARLE, Christophe; VERGER, Jacques. História das universidades. São Paulo: Editora da UNESP, 1996.

FORPROEX. Fórum de Pró-Reitores das Instituições Públicas de Educação Superior Brasileiras. Política Nacional de Extensão Universitária. 2012. Disponível em: https://proex.ufsc.br/files/2016/04/Pol\%C3\%ADtica-Nacional-de-Extens\%C3\%A3oUniversit\%C3\%A1ria-e-book.pdf. Acesso em: 25 maio 2020. 
FREIRE, Paulo. Extensão ou comunicação? 7. ed. Rio de Janeiro: Paz e Terra, 1983.

IMPERATORE, Simone Loureiro Brum; PEDDE, Valdir. "Curricularização" da Extensão Universitária no Brasil: questões estruturais e conjunturais de uma política pública In: XIII CONGRESO LATINOAMERICAN DE EXTENSIÓN UNIVERSITARIA. Anais... Havana, 2015. Disponível em:

http://curricularizacaodaextensao.ifsc.edu.br/files/2016/06/1_Artigo_Curricularizaca_da_Exte nsao_Universitaria_no_Brasil.pdf. Acesso em: 25 maio 2020.

JONES, Gwyn E.; GARFORTH, Chris. The history, development, and future of agricultural extension. In: SWANSON, Burton E.; BENTZ, Robert P.; SOFRANKO, Andrew J. (Eds.). Improving agricultural extension. A reference manual. Rome: Food and Agriculture Organization of the United Nations, 1998. p. 8-22.

LAWRIE, Alexandra. The University Extension Movement. In: LAWRIE, Alexandra (Org.). The Beginnings of University English. Extramural Study, 1885-1910. London: Palgrave Macmillan, 2014. p. 56-85.

MACIEL, Alderlândia da Silva. O princípio da indissociabilidade entre Ensino, Pesquisa e Extensão: um balanço do período 1988-2008. 2010. Tese (Doutorado em Educação) Universidade Metodista de Piracicaba, Piracicaba/SP, 2010.

MAZZILLI, Sueli. Ensino, pesquisa e extensão: reconfiguração da universidade brasileira em tempos de redemocratização do Estado. Revista Brasileira de Política e Administração da Educação, v. 27, n. 2, p. 205-221, maio/ago. 2011. Disponível em: https://seer.ufrgs.br/rbpae/article/view/24770. Acesso em: 2 jul. 2020.

ORESKES, Naomi; CONWAY, Erik M. Merchants of Doubt: how a handful of scientists obscured the truth on issues from tobacco smoke to global warming. New York: Bloomsbury, 2010.

PAULA, João Antônio de. A extensão universitária: história, conceito e propostas. Interfaces - Revista de Extensão, v. 1, n. 1, p. 5-23, 2013. Disponível em: https://periodicos.ufmg.br/index.php/revistainterfaces/article/view/18930. Acesso em: 2 jul. 2020.

UFAL. Universidade Federal de Alagoas. Resolução n. ${ }^{\circ}$ 04, de 19 de fevereiro de 2018. Disponível em: https://ufal.br/transparencia/documentos/resolucoes/2018/rco-n-04-de-19-022018.pdf/view. Acesso em: 25 maio 2020.

UFMG. Universidade Federal de Minas Gerais. Resolução n. ${ }^{\mathbf{1}}$ 12, de 22 de setembro de 2015. Disponível em: https://www.ufmg.br/boletim/bol1915/5.shtml. Acesso em: 25 maio 2020.

UFPEL. Universidade Federal de Pelotas. Guia de Integralização da Extensão nos Currículos de Graduação da UFPel. 2019. Disponível em: 
https://wp.ufpel.edu.br/prec/files/2019/05/Guia-de-integraliza\%C3\%A7\%C3\%A3o.pdf.

Acesso em: 25 maio 2020.

UFPE. Universidade Federal de Pernambuco. Resolução n. ${ }^{\circ}$ 9, de 2017. Disponível em: https://www.ufpe.br/documents/398575/400862/Res+2017+09+CCEPE.pdf/8ac4cadc-af4741b1-bed5-a7a63dfaeb42. Acesso em: 25 maio 2020.

UFSC. Universidade Federal de Santa Catarina. Resolução Normativa n. ${ }^{0}$

01/2020/CGRAD/Cex, de 3 de março de 2020. Disponível em:

https://curricularizacaodaextensao.ufsc.br/files/2020/03/resolu\%c3\%87\%c3\%83ocurriculariza\%c3\%87\%c3\%83o-da-extens\%c3\%83o-2-1.pdf. Acesso em: 25 maio 2020.

UFU. Universidade Federal de Uberlândia. Conselho de Graduação. Resolução n. ${ }^{0}$ 13, de 2019. Disponível em: http://www.reitoria.ufu.br/Resolucoes/resolucaoCONGRAD-201913.pdf. Acesso em: 25 maio 2020.

UNIFESP. Universidade Federal de São Paulo. Guia para curricularização das atividades de Extensão nos cursos de graduação da Universidade Federal de São Paulo. 2017.

Disponível em:

https://www.unifesp.br/reitoria/proec/images/proex/curriculariza\%c3\%a7\%c3\%a3o/guia_curr icularizacao_atividades_extensao_cursos_graduacao_unifesp_28.09.2017.pdf. Acesso em: 25 maio 2020.

WOLFF, Robert P. O ideal da universidade. São Paulo: Editora da Unesp, 1993.

Recebido em: 21/07/2020

Aprovado em: 21/12/2020 